\title{
Commentary
}

\section{Nurses frustration with the use of technology}

\section{Ayala Gonen* \\ Department of Nursing, Ruppin Academic Center, Emeq-Hefer, Israel}

Today, with the rapid progress of Information Computer Technologies (ICT) in health care, when using ICT is growing among various health professions, it is crucial to find out more information about nurses use of technology.

The nurse is the key person for the provision of a safe and effective care for her patients. Despite the rapidly changing health care environment, the nurse is the only healthcare professional who stay by the patient bedside 24 hours a day, 7 days a week, and actually, she is the most constant and stable factor for the patient and his family, creating a relationship with him, knowing the patient better than any other service provider in the field of health, and studying his desires, his fears, his abilities, and his challenges.

Adopting the use of technology in the workplace is not a simple process. McLuhan [1] and Meyrowitz [2] who examined the effect of adopting Technology use, found that the technology use bring some psychological, cognitive and sociological changes. In addition, Minsky [3] and Moores [4], claimed that beliefs and values, are the base of the discourse concerning using technology and they outline the ways to use it.

Given the fact that the nursing profession is largely female, it would be correct to focus on the link between technology and gender. There is a bidirectional relationship, between gender and technology. The feminist approaches speak about the gender relationship related to the technological patriarchal system, where the majority of men choose to work with technology, and the women are the victims. Other approaches tend to attribute the advanced implications for women entering the field of new technologies. These approaches allow flexibility in the gender relationship- differences between genders, concerning the use of technology also by women, and as a result, it is an opening for the reorganization of the gender differences [5-8]. Today, the integration of women in technology-oriented area is relatively very small. This can be explained due to cultural factors which make a link between masculine identity technologies, regardless of the women technological capacities of women to obtain technological knowledge. Women are seen as entities that designed to focus on human relationships, while men are seen in contact with machinery [5-9]. This situation is prominent at the ultra-Orthodox communities where, the social structure of the religious communities, dictate that women are responsible for household and raising the children, and they are perceived as engaging in human relationships, and they are not supposed to have high technological capabilities.

As it can be seen, most of the workers at the caring professions like teaching and nursing are women. McCallum, (2014) who studied the adoption of technology by teachers, found strong opposition to using ICT and says that there is great importance to the of teachers beliefs and their self-efficacy about their ability to perform.

From time immemorial, nursing is a profession that deals with humane treatment and its workers are usually motivated by giving and helping. Virginia Henderson [10], one of the theoretician of the nursing profession, claims that the only role of a kind of nurse is to assist the individual, sick or healthy, contributing to his health. Nursing is a profession based on giving, the nurse feel that she should be humane, friendly, accessible and ready to help and support the patient, all in order to truly represent the patient and family and help him to reach a state of well-being as much as possible. Studies show that still the main causes for choosing the nursing profession are giving vocation, mission, servicing $[11,12]$ have investigated the characteristics of choice of profession nurses of the millennium (those born after 1980), found that the choice of profession were moral motives, noble, altruistic and sense of compassion.

However, the $21^{\text {st }}$ century has brought many changes in the due to the digital area. The nursing profession today is not limited only to satisfy physiological needs, to provide medicines and to give holistic and humane patient care. Huston [13] marks the rapid development of seven important areas that have a great impact on the profession and we must be ready for them: Genetics and Genome, interventions less invasive and more technology, printing, three-dimensional, robotics, biometrics, a sick computer, and giving instructions to a computer which includes a Decision Support. In 2010, the United States institute of medicine [14] presented a position paper which includes a number of recommendations on the future of the nursing profession, which states that the nurses have to fill positions where their technological tools should help her to coordinate patient care. In addition, Jim Carroll, an American futurist known $[15,16]$ points out that health care knowledge doubling every six years, a fact that reinforces the need for change growing louder and adequate preparation

In this situation created frustration among nurses who had to focus their work as providers of patient care and family and to find levels of high technologies in the control of ICT for the purpose of patient care. On the one hand, the Academic nurses required learning and using as many technological means, on the other hand, the nurse feels the need to apply what she learned - a sense of obligation to handle direct care patient, help him and give him humane care based on their condition. This situation creates nurse feelings of frustration and a perception about a gap between the theoretical approaches that emphasize the human patient care and the demand to use multiple complicated technologies, so the big question is what is the essence of the nursing profession? Is it "high-tech", or "high touch", or it is a combination of both? That is why, the policymakers, the nursing managers and

Correspondence to: Ayala Gonen, $\mathrm{PhD}, \mathrm{RN}$, Department of Nursing, Ruppin Academic Center, Emeq Hefer, Israel 4025000; E-mail: ayala.gonen@gmail.com

Received: January 15, 2016; Accepted: January 20, 2016; Published: January 23, 2016 
educators must find the right ways to help nurses and guide them how to cope with ICT without lessening the sense of "high touch". The combination of "high-tech" with "high touch" will improve the efficiency and quality of patient care, diminishing the nurses frustration and achieving significant financial savings.

\section{About the author}

Dr. Ayala Gonen, has seniority and experience in health and nursing Information and Computer nursing (see CV) and currently employed at Ruppin Academic Center in the Department of Nursing lecturer researcher and deputy head of the department. Dr. Gonen is a pioneer implementer of the ICT in Israel and participated in many important projects started from design to implementation and evaluation. Dr. Gonen represents the area of nursing information and computing in Israel, published in well-known international professional journals and a member in international education working group.

\section{References}

1. McLuhan M (1965) Understanding Media: The extensions of man. New York: McGraw Hill.

2. Meyrowitz J (1985) No sense of place: The impact of electronic media on social behavior. New York: Oxford University Press.

3. Minsky M (1988) Society of mind. Simon and Schuster.
4. Moores S (1993) Interpreting audiences: the ethnography of media consumption. London: Sage.

5. Wajcman J (1994) Technology as masculine culture. The Polity Reader in Gender Studies 216-25.

6. Wajcman J (2010) Feminist theories of technology. Cambridge journal of economics 34: $143-152$.

7. Cockburn C (1992) The circuit of technology: Gender, identity and power.

8. Faulkner W (2001) The technology question in feminism: A view from feminist technology studies. Women's Studies International Forum 24: 79-95.

9. Cockburn C,Ormrod S (1993) Gender and technology in the making. London: Sage.

10. Henderson V (1964) The Nature of Nursing. Am J Nurs 64: 62-68. [Crossref]

11. Eley D, Eley R, Bertello M, Rogers-Clark C (2012) Why did I become a nurse? Personality traits and reasons for entering nursing. J AdvNurs 68: 1546-1555. [Crossref]

12. Price SL, McGillis Hall L, Angus JE, Peter E (2013) Choosing nursing as a career: a narrative analysis of Millennial nurses' career choice of virtue. NursInq 20: 305-316. [Crossref]

13. Huston C (2013) The impact of emerging technology on nursing care: warp speed ahead. Online J Issues Nurs 18: 1. [Crossref]

14. Institute of Medicine (2010) The future of nursing: Focus on education. Washington, DC: Institute of Medicine.

15. Carroll J (2011) Blog.

16. Salazar OA (2015) Humanized care: A challenge for nursing, International Archives of Nursing and Health Care Editorial.

Copyright: (C2016 Gonen A. This is an open-access article distributed under the terms of the Creative Commons Attribution License, which permits unrestricted use, distribution, and reproduction in any medium, provided the original author and source are credited. 